\title{
On the Unemployment-Output Relation in South Africa: A Non-Linear ARDL Approach
}

\author{
Brian Tavonga Mazorodze ${ }^{1}$, Noureen Siddiq ${ }^{2}$ \\ ${ }^{1}$ University of Zululand, Department of Economics, KwaDlangezwa, South Africa \\ 2University of Lahore, Department of Economics, Sargodha Campus, Pakistan \\ brianmazorodze@gmail.com,noreen.siddiq@yahoo.com
}

\begin{abstract}
The central aim of this paper is to establish the asymmetric effects of cyclical output on South Africa's unemployment rate. To achieve this objective, the non-linear autoregressive distributed lag model (NARDL) is applied on quarterly data spanning the periods 1994Q1-2017Q4. For every 10\% economic contraction and expansion respectively according to the results, the response of the labour market is asymmetric in the long-run in that it loses more workers during contraction $(10.3 \%)$ than it employs during recoveries (8\%) supporting the labour market hysteresis. This is particularly true post the 2009 Global crisis suggesting that firms might have become more risk-averse to short-lived recoveries in recent years. The weak response of the labour market during expansions supports IMF's recent proposition that economic recovery alone may not be enough to address South Africa's unemployment problem.
\end{abstract}

Keywords: Unemployment, Cyclical Output, Non-Linear ARDL, South Africa

\section{Introduction}

South Africa has faced the problem of unemployment since the advent of democracy. According to Statistics South Africa (Stats SA), its quarterly official unemployment rate has averaged $24 \%$ since 1994 and is currently stagnant at its highest rate of $27.7 \%$ in the post-Apartheid era. Joblessness according to the expanded definition rose to $36.4 \%$ from $35.6 \%$ in 2017 (IMF). In addition, the unemployment rate for persons below the age of 25, using the expanded definition, is $67.4 \%$. Such shockingly high rates of unemployment require close monitoring as they potentially create economic disorder such as organised crimes (Narayan and Smyth, 2004), social tensions and political instability. Given this background, the immediate question becomes: what is driving South Africa's unemployment rate? Although the role of structural factors, shortage of skill, inadequate private investment and low business confidence cannot be downplayed, two commonly held propositions at policy level are that recessionary episodes are massively destroying jobs while recoveries have not been robust enough to absorb labour. These propositions are grounded in the highly celebrated Okun's law which predicts an inverse relationship between cyclical output and the unemployment rate. In particular, the Okun's (1962) law stemmed from the observation that a 3 percentage point increase in the US' quarterly output growth was required to reduce the rate of unemployment by a margin of 1 percentage point. Despite this law having laid a foundation from which most empirical studies on unemployment-output have been based, it remains mulled by empirical debates on its validity with its criticisms ranging from a lack of a clear theoretical explanation to a lack of an appropriate functional form.

As a result, empirical model specifications on this subject have largely been influenced by statistical data considerations rather than the theory itself (Phiri, 2014). While empirical literature on this topic has grown rapidly, most of them (Lal et al., 2010., Alhawarin and Kreishan, 2010., Fatai \& Bankole., 2013, Leshoro, 2013., Tombolo and Hasegawa., 2014., Pehlivanoğlu and Tanga., 2016) are based on approaches that assume symmetry and linearity in the unemployment and cyclical output relation. It has been argued that the symmetric and linearity assumption on the unemployment-cyclical output relationship is restrictive and could be empirically misleading (see Cuaresma, 2003; Holmes and Silverstone, 2006). Take for instance Stats SA figures which confirm that agriculture lost 44000 jobs in 2018 on the back of droughts and weak economic performance. It is not reasonable to expect that exactly 44000 jobs will be created in agriculture if the economy recovers. In the words of Marinkov and Geldenhuys (2007), asymmetry in this case would imply that the rate of unemployment is either more (less) responsive to positive (negative) output changes and vice versa. There are several explanations as to why the labour market's response to output changes may be asymmetric and non-linear. First, there is a general tendency by firms to fire more workers during economic recessions than they employ when the economy recovers. Second as argued by Shin et al. (2014) and 
Blanchard and Summers (1986), this may be explained by the labour market hysteresis in which cyclical output shocks may have a permanent effect on structural unemployment.

Blanchard and Summers (1986) in particular argue that there is no systematic tendency for the labour market to revert back to its initial state even after the economy has fully recovered due to the asymmetric adjustment costs of labour. Several estimation techniques have been proposed thus far to accommodate asymmetries in macroeconomic relations and they include the threshold error correction model (TECM), smooth transition regression (STRECM) and the Markov-switching ECM among others. In this paper however, we apply the recent non-linear autoregressive-distributed-lag-model (NARDLM) proposed by Shin et al. (2014). The advantage of this approach over the others is that it incorporates the asymmetries both in the short and long-run irrespective of the underlying data generating process. In addition to that, when evaluating the speed and path of short-run adjustment, the NARDLM generates dynamic multipliers which do not require forecasting of any of the cointegrating variables and this feature makes it less susceptible to the common uncertainty surrounding the conventional impulse response analyses (Shin et al., 2014). Given these advantages, this paper contributes by applying the NARDLM approach in the context of South Africa. The rest of the paper proceeds as follows, section 2.0 provides literature review, section 3.0 outlines materials and methods 4.0 presents the empirical results while 5.0 provides a summary and policy implications.

\section{Literature Review}

Analysing the unemployment-output relationship has a long history in macroeconomics. Intuitively, this relationship can be broadly viewed as the connection between the labour market and the goods market and has mainly been examined within the auspices of the Okun's law. What the Okun's law posits is that changes in cyclical output are inversely related to changes in the unemployment rate. This relation is intuitive in that when the economy contracts, firms fire workers to cut production costs and when the economy recovers through demand management policies such as expansionary monetary and fiscal policies, firms begin to employ which later reduces the rate of actual unemployment. Such a mechanism happens especially when the economy is closing the gap between its actual output and its potential output otherwise at full potential output, the goods and the labour market will be at equilibrium such that the labour market will only be characterised by the natural rate of unemployment which may not be influenced by demand management policies. The Okun's law is central in the formulation of aggregate supply-side models by combining it with the Phillips-curve. It also provides a benchmark when measuring the cost of unemployment such as the effectiveness of a disinflationary policy (Jardin and Gaétan, 2011). Notwithstanding its relevance and simplicity in understanding the labour-goods market connection, an important issue drawn from the literature relates to its lack of a clear and robust specification (Phiri, 2014). Knotek (2007) for instance argue that the Okun's law is a statistical and not a structural macroeconomic relationship hence it does not have a unique functional form that has been predominantly preferred to the other (Weber, 1995). As a result, studies testing the validity of the Okun's law have done so using different specifications guided by data properties and statistical tests on the appropriate functional form.

Empirically, there is a common understanding today that the relationship between the unemployment rate and output changes is asymmetric and non-linear owing to a number of theoretical reasons. First as argued by the labour market hysteresis, firms tend to fire more workers during a recession and employ less during economic expansion. The fear of having a short-lived expansion coupled with the need to recover lost profit during a recession explains why firms may be reluctant to employ more workers when the economy expands. The second reason may be restrictive interventions by the state and labour market institutions. For example, firms may be unable to fire workers in the short-run due to labour laws that may not allow the firing of workers at short notice. The insiders-outsiders theoretical model has also been used to explain why the unemployment rate may not return to its initial level when the economy recovers. According to this theoretical model, negative shocks which increase the unemployment rate increases the number of unemployed workers (outsiders) and reduces the number of insiders (currently employed workers). Insiders have a bargaining power hence they can set the equilibrium-wages which ensure and secures their own and not the outsiders'. This phenomenon explains the persistence of unemployment even when the recession ends (Jardin and Gaétan, 2011). Empirically, Lee (2000) concludes that output significantly affects employment but the relationship is unstable over time. For South Africa, Geidenhuys and Marinkov (2007) 
confirm validity of Okun's law and that the relation is asymmetric. Similarly, Villaverde and Maza (2009) conduct a test for the output-employment relation in the case of Spain between 1990 and 2004 and find the Okun's holding but argue that Okun's estimates vary from region to region due to productivity differences. Moosa (1999) estimates Okun's coefficients for the US economy based on quarterly data from 1947 to 1992.

Coefficients from Harvey's structural time series technique are found to be -0.16 and -0.38 for the short-run and the long-run respectively. Also confirmed is that that the coefficients from the dynamic model are closer to the Okun's coefficients. In the case of Pakistan, Javed (2005) examine the association between the unemployment rate and output growth based on annual time series data for the time period $1981-2005$. Results from the error correction mechanism confirm an inverse and long-run association between the rate of unemployment and output growth. Fatai and Bankole (2013) tested the validity of Okun's law in the case of Nigeria, relying on annual time series data between 1980 and 2008. Results from the fully modified ordinary least squares method reveal a positive coefficient which implies a rejection of the Okun's law. In the Swedish economy, Arshad and Erixon (2010) applies the error correction model and find results supportive of the Okun's law. Contrary to that in the case of Jordan, Kreishan (2011) do not find the Okun's law holding suggesting that economic output cannot solve the unemployment problem. For Driouche (2013), the link between growth and unemployment is found to be statistically insignificant, in the long-run for Algeria. The majority of studies above rely on estimation approaches that assume symmetry and linearity which could be empirically misleading. The asymmetric relation between the labour market and output changes has long been validated in earlier studies such as Bodman (1998), Acemoglu and Scott (1994), Lee (2000), Cuaresma (2003) and more recently Beaton (2010) and Phiri (2014). Jardin and Gaétan (2011) apply a semi-parametric non-linear approach and find evidence of a non-linear Okun's law among European countries supporting the view that unemployment responds more to economic contraction than economic expansion and they attribute this non-linear behaviour to the risk version phenomena of firms.

Cevik, Dibooglu and Barişik (2013) rely on the Markov Regime Switching Model and find that Markov Regime Switching Model has more predominant results relative to linear models. For South Africa, Phiri (2014) applies a Threshold Adjustment Model and confirm an asymmetric relation between unemployment and output changes. Marinkov and Geldenhuys (2007), between 1970 and 2005, in South Africa find evidence of asymmetries. Other studies such as Leshoro (2013), Tombolo and Hasegawa (2014), Pehlivanoğlu and Tanga (2016) have assumed symmetry and linearity when examining the validity of Okun's law. Leshoro (2013) does not find causation from growth to unemployment while Pehlivanoğlu and Tanga (2016) do not find the Okun's law valid in South Africa. Banda and Choga (2016) apply the Johansen cointegration test and confirm a positive impact of GDP on unemployment. The available evidence clearly suggests that the debate on unemployment and output remains on-going which necessitates further empirical evidence on the matter. Our paper contributes to this discussion by ascertaining the asymmetrical effects of cyclical output on the rate of unemployment for South Africa. It also applies a dataset that stretches up to the $4^{\text {th }}$ quarter of 2017 which makes it likely to capture recent output dynamics.

\section{Methodology}

Our analysis is based on quarterly data spanning the periods 1994Q1 - 2017Q4. Selection of this sampling period is influenced by data availability on the unemployment rate. Despite the data availability issue, this sampling period starts from the first quarter of the year in which South Africa attained independence hence the analysis can be interpreted as evidence of the output-unemployment relationship in the democratic era. By definition, unemployment is measured by the official unemployment rate while output is seasonally adjusted GDP per capita at constant prices $(2010=100)$. Data are sourced from South African Reserve Bank (SARB).

Model Specification: The empirical model applied in this paper is theoretically based on the Okun's law following most studies in literature. Okun (1962) considered several specifications which fall under two broad categories namely the difference approach and the gap approach. The former regresses differenced quarterly unemployment rate on differenced output while the later estimates the cyclical unemployment cyclical output relation. In addition to the cyclical unemployment - cyclical output relation, Okun (1962) also 
considered a version that relates the level of the unemployment to the cyclical output. In this paper, we consider this last specification and it takes the following form.

$$
\begin{gathered}
U_{t}=\vartheta_{0}+\vartheta_{1}\left(Y_{t}^{A}-Y_{t}^{*}\right)+\varepsilon_{t} \\
t=1994 Q 1, \ldots, 2017 Q 4
\end{gathered}
$$

where subscript $\mathrm{t}$ denotes time in quarters, $\mathrm{U}$ signals the level of official unemployment rate, $Y_{t}^{A}$ represents actual output and $Y_{t}^{*}$ denotes the time-varying path of potential output so that $Y_{t}^{A}-Y_{t}^{*}$ measures output gap $\left(Y_{t}^{C}\right)$. Put differently, the gap between observed output and potential output measures the level of cyclical output. Parameter $\vartheta_{0}$ is the intercept while $\vartheta_{1}$ is the slope estimate of interest which governs how unemployment rate links with cyclical output. The random term, represented by $\varepsilon_{t}$, and is expected to be white-noise. The challenge with defining the output gap i.e. $Y_{t}^{A}-Y_{t}^{*}$ is that $Y_{t}^{*}$ is unobserved and hence has to be estimated. This creates uncertainty as the choice of an estimation technique may significantly influence the final results. In this paper, the Hodrick-Prescott filter method proposed by Hodrick and Prescott (1997) is applied $^{1}$. This technique essentially categorises a time series into a two elements - cyclical component $\left(c_{t}\right)$ and the trend $\left(T_{t}\right)$. Assuming therefore that the time series is generated by the process $J_{t}=T_{t}+c_{t}+\mu_{t}$, then a positive of the multiplier $\lambda$ exists so that $T$ solves the following minimization problem:

$$
\min _{\tau}\left(\sum_{t=1}^{T}\left(J_{t}-T_{t}\right)^{2}+\lambda \sum_{t=2}^{T-1}\left[\left(T_{t+1}-T_{t}\right)-\left(T_{t}-T_{t-1}\right)\right]^{2}\right)
$$

The first term i.e. squared deviations, $\left(J_{t}-T_{t}\right)^{2}$ penalizes short-run cyclical fluctuations in the time series $J$ while the second multiple term penalizes the time series' deviations in the growth of J's trend (Hodrick and Prescott, 1997). Parameter $\lambda$ is assumed to be 1600 (Hodrick and Prescott, 1997) since we are dealing with quarterly data. Having generated the cyclical output as represented in our model by $Y^{C}$, we proceed to respecify equation (1) into a dynamic model and apply the ARDL bounds testing procedure. This procedure is selected for several reasons. First, relative to the Johansen multivariate co-integration test, the ARDL provides super-consistent estimates particularly in small samples (Narayan and Narayan, 2005). The alternative EngleGranger (1987) approach is exposed to small sample bias as argued by Mah (2000). Second, the ARDL bounds testing procedure can be applied even if the underlying covariates have an I (0) and 1(1) mixture of integration (Pesaran and Shin, 2001). Third, it deals with endogeneity problems and handles well hypothesis testing on long-run coefficients unlike the Engle and Granger (1987). Accordingly, the bound testing procedure addresses endogeneity problems when the optimum lags are included, and it simultaneously allows one to correct for serial correlation in residuals. Fourth, unlike the Engle-Granger approach, the ARDL bounds testing procedure possess a desirable statistical property that it does not necessarily forces the shortrun dynamics of the model into the residuals (Pattichis, 1999). Fifth, both the long-run and short-run model parameters can be simultaneously estimated. The conventional linear ARDL with our two variables in an unrestricted error correction representation form looks as follows:

$$
\Delta U_{t}=\delta_{0}+\delta_{1} U_{t-1}+\delta_{2} Y_{t-1}^{C}+\sum_{j=1}^{p-1} \gamma_{j} \Delta U_{t-j}+\sum_{j=0}^{q-1} \emptyset_{j} \Delta Y_{t-j}^{C}+\varepsilon_{t}
$$

$\&$

$$
Y^{C}{ }_{t}=Y_{t}^{A}-Y_{t}^{*}
$$

This specification assumes linearity and symmetry in the way cyclical output affects unemployment which is too restrictive given the potential non-linarites in the way these two variables relate. Jardin and Gaétan (2011) for instance argue that the assumption of linearity and symmetry when modelling the unemploymentoutput relationship produces misleading forecasts. As a result, we improve specification (2) by re-specifying it in the form of a non-linear (NA0RDL) suggested by Shin et al. (2014). The NARDL starts by decomposing cyclical output into positive and negative changes so that the effect of economic expansion and economic contraction on unemployment can be established respectively.

Where

$$
Y^{C}{ }_{t}=Y_{0}^{C}+Y_{t}^{C+}+Y_{t}^{C-}
$$

$$
Y_{t}^{C+}=\sum_{i=1}^{t} \Delta Y_{t}^{C+}=\sum_{i=1}^{t} \max \left(\Delta Y_{i}, 0\right)
$$

\footnotetext{
${ }^{1}$ Robustness checks indicated that the choice of alternative methods did not significantly change the central result of the paper.
} 
$\&$

Where

$$
Y_{t}^{C-}=\sum_{i=1}^{t} \Delta Y_{t}^{C-}=\sum_{i=1}^{t} \min \left(\Delta Y_{i}, 0\right)
$$

The long-run association between $U_{t}$ and $Y_{t}^{C}$ is thus given by:

$$
\Delta Y_{t}^{C}=Y_{t}^{C}-Y_{t}^{C}{ }_{t-1}
$$

$$
U_{t}=B_{0}+B^{+} Y_{t}^{C+}+B^{-} Y_{t}^{C-}+\varepsilon_{t}
$$

where symbols $B^{+}$and $B^{-}$represent the long-run coefficients to be estimated for positive and negative changes in $Y_{t}^{C}$ respectively. From a theoretical viewpoint, the labour market hysteresis postulates that the rate of unemployment rate reacts more strongly to economic recessions than to booms hence we expect $\left|B^{+}\right|<\left|B^{-}\right|$. Following Shin et al. (2014), we can transform equation (2) into an unrestricted or conditional error correction form of a non-linear ARDL model:

$$
\begin{gathered}
\Delta U_{t}=\vartheta_{0}+\delta U_{t-1}+\theta^{+} Y_{t-1}^{C+}+\theta^{-} Y_{t-1}^{C-} \sum_{i=1}^{p-1} \gamma_{j} \Delta U_{t-i}+\sum_{i=0}^{q-1}\left(\varphi_{i}^{+} \Delta Y_{t-1}^{C+}+\varphi_{i}^{-} \Delta Y_{t-1}^{C-}\right) \\
+\varepsilon_{t}
\end{gathered}
$$

The positive (+) and negative (-) signs in equation (7) are essentially positive and negative partial sum processes and symbol $\mathrm{p}$ represents the lag order of the differenced unemployment rate while $\mathrm{q}$ is for the distributed exogenous variable. The NARDL model firstly estimates equation (7) by the conventional OLS approach and tests for an asymmetric cointegrating relationship between $Y_{t}^{C}$ and $U_{t}$. The null hypothesis of no long-run relationship i.e. $\delta=\theta^{+}=\theta^{-}=0$ can be tested using an $F$ test. Thirdly, long-run and short-run asymmetry is tested with the former being represented by the test for $\theta^{+}=\theta^{-}$via a standard Wald test. Short-run strong form symmetries requires:

while weak short-run symmetry requires:

$$
\begin{gathered}
\varphi_{j}^{+}=\varphi_{j}^{-} \\
\text {for all } j=1, \ldots, q=1
\end{gathered}
$$

$$
\sum_{j=0}^{q-1} \varphi_{j}^{+}=\sum_{j=0}^{q-1} \varphi_{j}^{-}
$$

The last step of the NARDL procedure derives the positive and negative multipliers with $Y_{j}^{C+}$ and $Y_{j}^{C-}$ computed as:

$\&$

$$
m_{h}^{+}=\sum_{j}^{h} \partial U_{t+j} / \partial Y_{T}^{C+}
$$

$$
m_{h}^{-}=\sum_{j}^{h} \partial U_{t+j} / \partial Y_{T}^{C-}
$$

where $h=0,1,2, .$. for $Y_{t}^{C+}$ and $Y_{t}^{C-}$ respectively. Noteworthy is that $h \rightarrow \infty, m_{h}^{+} \rightarrow \beta^{+}$and $m_{h}^{-} \rightarrow \beta^{-}$. These dynamic multipliers add useful information towards the analyses of the asymmetric adjustment path taken by the model following a short-run disequilibrium with initial positive or negative partial cyclical output. The NARDL model requires none of the variables to be I (2). Therefore, we first perform stationary tests to make sure that none of the variables violates this condition. We use the break-point unit root test which is essentially a modified Augmented Dickey Fuller test that accommodates structural breaks considering that standard tests for stationary such as the ADF test, Elliot, Rothenberg and Stock (ERS) and Phillips-Perron (PP) are generally biased towards a false null hypothesis if the time series has a structural break (Bai and Perron, 1998). 


\section{Results and Discussion}

Table 1 reports Breakpoint unit root tests results. With and without the trend in the specification, the rate of unemployment in South Africa is generated by a non-stationary process but is integrated of order one. On the other hand, the cyclical output series is integrated of order zero.

Table 1: Break Point Unit Root Test

\begin{tabular}{clllll}
\hline Variable & \multicolumn{1}{l}{$\begin{array}{l}\text { Innovation Break-Type } \\
\text { Intercept }\end{array}$} & $\begin{array}{c}\text { Intercept \& } \\
\text { trend }\end{array}$ & Intercept & $\begin{array}{c}\text { Additive Break-Type } \\
\text { Intercept \& } \\
\text { trend }\end{array}$ & $\begin{array}{c}\text { Order of } \\
\text { Integration }\end{array}$ \\
\hline$U$ & -3.733 & -4.091 & -3.685 & -4.134 & $\mathrm{I}(1)$ \\
$\Delta U$ & $-11.304^{* * *}$ & $-11.246^{* * *}$ & $-11.425^{* * *}$ & $-11.391^{* * *}$ & \\
$Y^{C}$ & $-4.578^{* *}$ & $-4.737^{*}$ & $-4.997^{* * *}$ & -4.988 & $\mathrm{I}(0)$ \\
$\Delta Y^{C}$ & -------- & ------- & ----- & --- & \\
\hline
\end{tabular}

Note: $*, * *, * * *$ denotes $\mathrm{p}<0.1, \mathrm{p}<0.05 \& \mathrm{p}<0.01$ respectively. Corresponding probability values represent Vogelsang (1993) asymptotic one-sided p-values.

The results in table 1 provide justification for the non-linear ARDL approach since none of the model variables is I (2). The non-linear ARDL bounds testing depends on four factors (i) number of regressors (k), (ii) assumption about the intercept and trend in the cointegrating equation, (iii) number of observations (n) and (iv) whether variables are I( 0 ) and (I(1). Here, $n=96, k=1$ since positive and negative cyclical output changes are constructed from one variable, assumption III, intercept and no trend and an I(1) and I(0) variable. The non-linear ARDL bounds testing procedure is performed after the estimation of equation (7). Based on the Schwarz Information Criterion (SIC), a non-linear ARDL $(1,0,0)$ is selected (see figure 3 in the appendix). Bounds testing results are therefore presented in table 2. The F-statistic of 6.89 is above 5.85 implying that we cannot reject the null hypothesis. This means unemployment, cyclical dips and booms move together in the long-run.

Table 2: Non-Linear ARDL Bounds Testing Procedure

\begin{tabular}{|c|c|c|c|c|c|c|c|}
\hline Dependent Variable & & $\mathrm{I}$ & ion & & & & F-statistic \\
\hline$U_{t}$ & & & & $Y_{t}^{C+}, 1$ & & & 6.89 \\
\hline & & & & & & & \\
\hline Critical Values & $\mathrm{I}(0)$ & $\mathrm{I}(1)$ & $\mathrm{I}(0)$ & $\mathrm{I}(1)$ & $\mathrm{I}(0)$ & $\mathrm{I}(1)$ & \\
\hline & 6.34 & 7.52 & 4.87 & 5.85 & 4.19 & 5.06 & \\
\hline
\end{tabular}

Note: Asymptotic critical values are based on Case III - unrestricted intercept and no trend

Having established the presence of a long-run relationship, we present long-run estimates in table 3. Both in terms of size and statistical significance, the results show that unemployment responds more to economic dips (represented by negative cyclical output changes) than economic booms (represented by positive cyclical output changes). The coefficient of positive output changes is negative and significant at $5 \%$ level. The interpretation of this coefficient is that the unemployment rate falls by 0.803 percentage points in the longrun if cyclical output increases by one unit. On the other hand, the coefficient associated with negative output changes is larger, negative and significant at $1 \%$ level. The interpretation of this coefficient is that a reduction of cyclical output by one unit raises the unemployment rate by 1.03 percentage points in the long-run. This result clearly indicates that South Africa's labour market is more responsive to economic recessions than economic expansions. Judging on the size of the coefficients, we can infer some asymmetries in that more workers are fired when the economy dips but less of them are employed when the economy recovers. This result is consistent with that observed in Jardin and Gaétan (2011) using a different methodology. Their findings strongly support that the effect of output changes on the unemployment rate is larger when the economy is contracting that when the economy is recovering. The asymmetries are theoretically consistent with the labour market hysteresis which says that the labour market responds more strongly to economic dips than economic booms. A formal test is conducted to check whether the effect is truly asymmetric. Results from the lower part of table 1 show that the null hypothesis of long-run symmetry is rejected at $1 \%$ level which validates the hypothesis that the labour market's response to changes in cyclical output is indeed 
asymmetric. Given this result, imposing the symmetry and linear restriction on the unemployment-output relationship could produce misleading policy inference.

Table 3: Long-Run Coefficients (Total Sample)

\begin{tabular}{|c|c|c|c|c|c|}
\hline Variable & & Coefficient & Std. Error & t-Statistic & Prob. \\
\hline$Y_{t}^{C+}$ & $\theta^{+}$ & -0.802754 & 0.371905 & -2.158492 & 0.0336 \\
\hline$Y_{t}^{C-}$ & $\theta^{-}$ & -1.034448 & 0.331479 & -3.120708 & 0.0024 \\
\hline $\mathrm{C}$ & & 0.232097 & 0.020939 & 11.084539 & 0.0000 \\
\hline Long-run Symmetr & & $\theta^{+}=\theta$ & F stat $=7.19$ & & 0.0087 \\
\hline
\end{tabular}

We proceed to decompose the sample into two sub-samples in order to check whether the relationship has changed over time. The first sub-sample comprises the period 1994Q1 - 2008Q4 while the second subsample comprises the 2009Q1 - 2017Q4. This decomposition is interesting in that it enables us to establish the output-unemployment relationship pre and post the 2009 Global Economic Recession. Results in table 4 reveal some interesting observations. First, we observe that the relationship between the two has changed in recent years. In particular, the results show that in the build-up to the 2009 Global Economic Recession, economic expansions did not significantly reduce South Africa's unemployment rate while economic contractions significantly increased the rate of unemployment. The former result echoes the sentiment that for the best part of the period since 1994, South Africa has experienced "jobless growth." This means that whenever the economy grew during this period, it did so without creating enough jobs. This is in line with the IMF's recent proposition that economic recoveries alone may be necessary but not sufficient to address the unemployment problem in South Africa. Another observation is that post the Global Economic Recession; the negative effect of economic recessions on job creation has become stronger (-1.307) relative to the pre-crisis period (-0.91). At the same time, the effect of economic recoveries turns out to be statistically significant but relatively lower in terms of size after the crisis (0.639) as compared to the period before the crisis. These two observations i.e. the increase in the number of people losing jobs during recession versus the decrease in the number of jobs created during recoveries, could reflect the fact that firms have become more risk averse on account of short-lived economic booms post the crisis period.

Table 4: Long-Run Coefficients Pre and Post the 2009 Global Crisis

\begin{tabular}{|c|c|c|c|c|}
\hline Variable & $\begin{array}{l}\text { 1994Q1-2008Q4 } \\
\text { Coefficient }\end{array}$ & Prob & $\begin{array}{l}\text { 2009Q1-2017Q4 } \\
\text { Coefficient }\end{array}$ & Prob \\
\hline $\begin{array}{ccc} & Y_{t}^{C+} & \theta^{+} \\
& Y_{t}^{C-} & \theta^{-} \\
\text {C } & & \end{array}$ & $\begin{array}{l}-0.735883 \\
-0.919242 \\
0.234689\end{array}$ & $\begin{array}{l}0.1409 \\
0.0202 \\
0.0000\end{array}$ & $\begin{array}{l}-0.639494 \\
-1.307275 \\
0.160664\end{array}$ & $\begin{array}{l}0.0093 \\
0.0001 \\
0.0000\end{array}$ \\
\hline Long-run Symmetry & $\theta^{+}=\theta^{-}$ & 0.0814 & & 0.0533 \\
\hline
\end{tabular}

The change in the unemployment-output relationship reported in table 4 is also confirmed in Owyang and Sekhposyan (2012) in the context of US. The model's short-run dynamics are presented in table 5 for the total sample. Judging by the sizes of the coefficients, the labour market still appears to respond more to the recession (0.14) than to recoveries (0.18) albeit slightly. Both the negative and positive changes have expected negative signs suggesting that increases in cyclical output reduce the unemployment rate while reductions in a cyclical output increase the unemployment rate. A formal test however does not find enough evidence reject the null hypothesis of symmetry as the probability value, 0.2117 , is above $10 \%$. This confirms that South Africa's labour market response to output changes is symmetrical and asymmetrical in the shortrun and long-run respectively. The symmetrical short-run response is perhaps not surprising given the prevalence of restrictive labour unions in South Africa. The symmetrical labour market response to changes in cyclical output in the short-run confirmed here for South Africa has also been confirmed in other countries where there is the presence of restrictive labour institutions. 
Shin et al. (2014) for instance confirmed a similar result in the case of Japan where restrictive labour institutions are highly prevalent. For South Africa, the interventions of labour unions in the labour market may also account for the slow short-run speed of adjustment, 0.177 , which shows that only $17.7 \%$ of shortrun disequilibrium is corrected each quarter. Noteworthy is that the significant connection between output changes and the rate of unemployment confirmed in table 5 contradicts with finds reported in Pehlivanoğlu and Tanga (2016) for South Africa. The difference could be emanating from the fact that they assumed linearity and symmetry. Shin et al. (2014) argue that studies based on the restrictive symmetric and linearity assumption can be suspects given the empirically asymmetrical response of the labour market. The short-run symmetrical relationship can be inferred through dynamic multipliers in figure 1 where the labour market is equally slow to respond to both negative and positive changes in cyclical output. The response gradually increases with time and becomes stronger in the long-run for negative output shocks relative to positive shocks. This corroborates the results reported in table 3 and 5. This kind of response is quite similar and to the response reported in Shin et al. (2014) in the context of the Japanese labour market which bears many features in common with South Africa.

Figure 1: Dynamic Multipliers for South Africa (Total Sample)

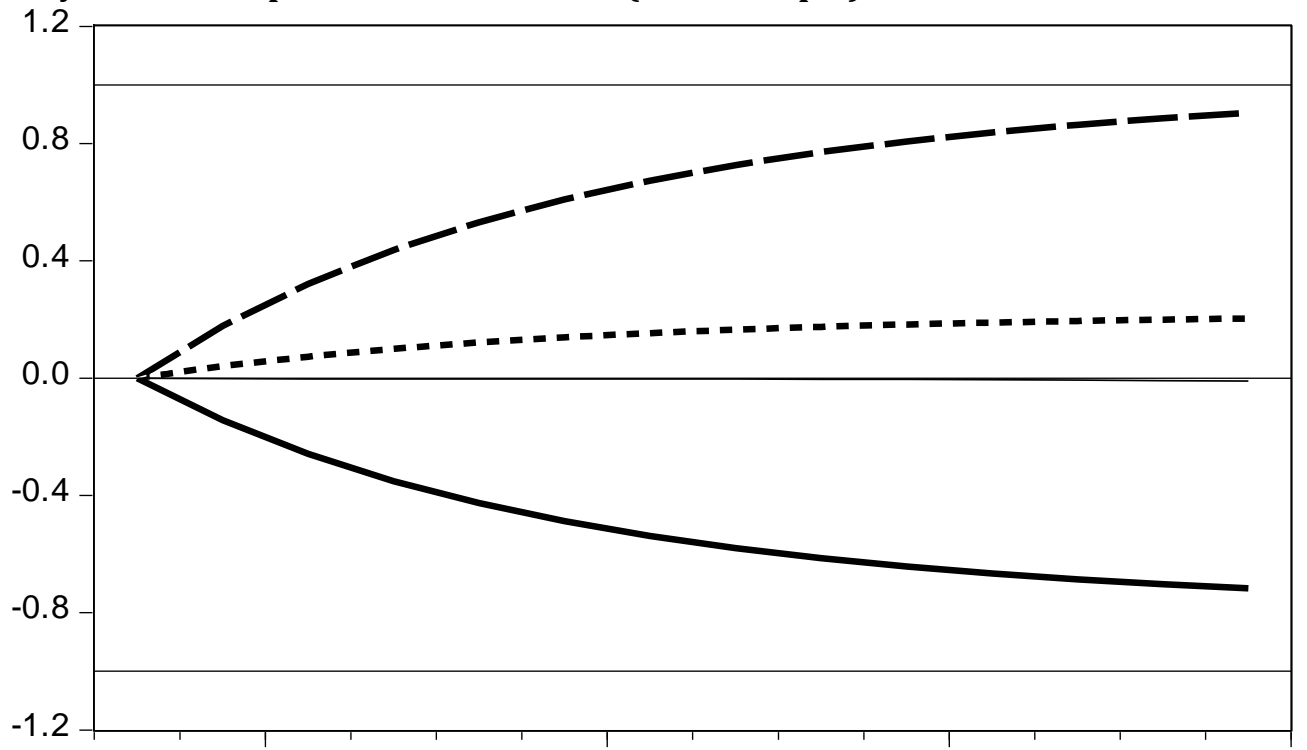

Y $+1 \%$ - $\mathrm{Y}-1 \%$ - Difference

To check for model adequacy, the baseline model was subjected to a battery of diagnostic tests and the results presented in the appendix section clearly show that none of the relevant diagnostics was violated. In particular, the model does not suffer from autocorrelation, heteroscedasticity, model misspecification, residual non-normality and parameter instability. Overall, our main result is consistent with previous literature that confirms non-linearities in the unemployment-output relationship (Cuaresma, 2003, Cevik, Dibooglu and Barişik, 2013, Phiri, 2014, Marinkov and Geldenhuys, 2007). Despite the use of different functional forms, the results demonstrate that the labour market responds in the same way to economic recessions and economic contractions in the short-run while the long-run effect is asymmetric.

Table 5: Short-Run Error Correction Model (Total Sample)

\begin{tabular}{ccccccc}
\hline Variable & & Coefficient & Std. Error & t-Statistic & Prob. & \\
\hline$\Delta Y_{t}^{C+}$ & $\varphi^{+}$ & -0.142270 & 0.043691 & -3.256267 & 0.0016 & \\
$\Delta Y_{t}^{C-}$ & $\varphi^{-}$ & -0.183333 & 0.054400 & -3.370062 & 0.0011 & \\
\multicolumn{2}{l}{$\begin{array}{l}\text { COINT EQ(-1) } \\
\text { Short-run Symmetry }\end{array}$} & -0.177228 & 0.061993 & -2.858832 & 0.0053 & \\
\hline
\end{tabular}




\section{Conclusion}

The relationship between cyclical output and the rate of unemployment has been examined for South Africa using the recently developed Non-Linear ARDL to capture non-linearities and asymmetries. The main result is that the labour market's response is symmetric in the short-run and is characterised by a slow speed of adjustment. Secondly, we find that the response of the labour market is asymmetric in the long-run and that it responds more strongly to economic dips than to economic booms. The evidence has suggested that in the long run, the labour market loses more workers than it employs during recoveries and this result is found to be particularly true for the post-2009 Global Economic Recession period. The weak response of the labour market to economic expansion implies that economic booms may not be sufficient in attenuating the unemployment problem in South Africa. Put differently, short-run macroeconomic stabilization tools such as the fiscal and monetary policies may not suffice in reducing the high unemployment rate prevailing in South Africa.

Declaration of Interest Statement: We declare no conflict of interest.

\section{References}

Acemoglu, D. \& Scott, A. (1994). Asymmetries in the cyclical behaviour of UK labour markets. The Economic Journal, 1303-1323.

Alhawarin, I. M. \& Kreishan, F. M. (2010). An Analysis of Long-Term Unemployment (LTU) in Jordan's Labor Market. European journal of social sciences, 15(1), 56-65.

Arshad, Z. \& Erixon, L. (2010). The Validity of Okun's Law in the Swedish Economy. Stockholm: Department of Economics Stockholm University.

Banda, H. \& Choga, I. (2016). The impact of economic growth on unemployment in South Africa: 1994-2012.

Beaton, K. (2010). Time variation in Okun's law: A Canada and US comparison (No. 2010, 7). Bank of Canada Working Paper.

Blanchard, O. J. \& Summers, L. H. (1986). Hysteresis and the European unemployment problem. NBER macroeconomics annual, 1, 15-78.

Bodman, P. M. (1998). Asymmetry and duration dependence in Australian GDP and unemployment. Economic Record, 74(227), 399-411.

Cevik, E. I., Dibooglu, S. \& Barişik, S. (2013). Asymmetry in the unemployment-output relationship over the business cycle: evidence from transition economies. Comparative Economic Studies, 55(4), 557-581.

Cuaresma, J. C. (2003). Okun's law revisited. Oxford Bulletin of Economics and Statistics, 65(4), 439-451.

Driouche, D. (2013). Economic Growth and Unemployment in Algeria: An Econometric Study, Al-Najah University Journal for Research, 27, 6, 1301-1318.

Engle, R. F. \& Granger, C. W. (1987). Co-integration and error correction: representation, estimation, and testing. Econometrica: Journal of the Econometric Society, 251-276.

Fatai, B. O. \& Bankole, A. (2013). Empirical test of Okun's Law in Nigeria. International Journal of Economic Practices and Theories, 3(3), 227-231.

Geidenhuys, J. \& Marinkov, M. (2007). Robust estimates of Okun's coefficient for South Africa, Working Paper.

Hodrick, R. J. \& Prescott, E. C. (1997). Post-war US business cycles: an empirical investigation. Journal of Money, credit, and Banking, 1-16.

Holmes, M. J. \& Silverstone, B. (2006). Okun's law, asymmetries and jobless recoveries in the United States: A Markov-switching approach. Economics Letters, 92(2), 293-299.

Huang, S. M., Wei, C. W., Yu, P. T. \& Kuo, T. Y. (2005). An empirical investigation on learners' acceptance of elearning for public unemployment vocational training. International journal of innovation and learning, 3(2), 174-185.

Jardin, M. \& Gaétan, S. (2011). How Okun's law is non-linear in Europe: a semi-parametric approach. Rennes, University of Rennes.

Javed, U. (2005). Okun's law: empirical evidence from Pakistan 1981-2005, master thesis, Södertörn University, School of Social Sciences, Sweden.

Knotek, II, E. S. (2007). How useful is Okun's law. Economic Review-Federal Reserve Bank of Kansas City, 92(4), 73. 
Kreishan, F. M. (2011). Economic growth and unemployment: An empirical analysis. Journal of Social Sciences, $7(2), 228-231$.

Lal, I., Muhammad, S., Jalil, M. A. \& Hussain, A. (2010). Test of Okun's law in some Asian countries cointegration approach.

Lee, J. (2000). The robustness of Okun's law: Evidence from OECD countries. Journal of Macroeconomics, 22(2), 331-356.

Leshoro, T. L. (2013). Does Economic Growth Lead Employment in South Africa? Journal of Economics and Behavioral Studies, 5(6), 336.

Mah, J. S. (2000). An empirical examination of the disaggregated import demand of Korea-the case of information technology products. Journal of Asian Economics, 11(2), 237-244.

Marinkov, M. \& Geldenhuys, J. P. (2007). Cyclical unemployment and cyclical output: An estimation of Okun's coefficient for South Africa. South African Journal of Economics, 75(3), 373-390.

Moosa, I. A. (1999). Cyclical output, cyclical unemployment, and Okun's coefficient a structural time series approach. International Review of Economics \& Finance, 8(3), 293-304.

Narayan, S. \& Narayan, P. K. (2005). An empirical analysis of Fiji's import demand function. Journal of Economic Studies, 32(2), 158-168.

Narayan, P. K. \& Smyth, R. (2004). Crime rates, male youth unemployment and real income in Australia: evidence from Granger causality tests. Applied Economics, 36(18), 2079-2095.

Okun, A. M. (1962). Potential GNP: Its Measurement and Significance. In Proceedings of the Business and Economics Statistics Section. Alexandria, VA: American Statistical Association, 98-10

Owyang, M. T. \& Sekhposyan, T. (2012). Okun's law over the business cycle: was the great recession all that different? Federal Reserve Bank of St. Louis Review, 94(September/October 2012).

Pattichis, C. A. (1999). Price and income elasticities of disaggregated import demand: results from UECMs and an application. Applied Economics, 31(9), 1061-1071.

Pehlivanoğlu, F. \& Tanga, M. (2016). An Analysis of the Validity of Okun's Law: Case of Turkey and BRICS. Uluslararası Ekonomik Araștırmalar Dergisi, 2(3).

Bai, J. \& Perron, P. (1998). Estimating and testing linear models with multiple structural changes. Econometrica, 47-78.

Pesaran, M. H., Shin, Y. \& Smith, R. J. (2001). Bounds testing approaches to the analysis of level relationships. Journal of applied econometrics, 16(3), 289-326.

Phiri, A. (2014). Nonlinear co-integration between unemployment and economic growth in South Africa. Managing Global Transitions, 12(4), 303.

Shin, Y., Yu, B. \& Greenwood-Nimmo, M. (2014). Modelling asymmetric cointegration and dynamic multipliers in a nonlinear ARDL framework. In Festschrift in Honor of Peter Schmidt (pp. 281-314). Springer, New York, NY.

Tombolo, G. A. \& Hasegawa, M. M. (2014). Okun's law: evidence for the Brazilian economy.

Villaverde, J. \& Maza, A. (2009). The robustness of Okun's law in Spain, 1980-2004: Regional evidence. Journal of Policy Modelling, 31(2), 289-297.

Weber, C. E. (1995). Cyclical output, cyclical unemployment, and Okun's coefficient: A new approach. Journal of applied econometrics, 10(4), 433-445. 


\section{Appendices}

\section{Diagnostic Tests}

Ramsey RESET Test

Equation: NARDL01

Specification: UNEM UNEM(-1) Y_NEG Y_POS C

Omitted Variables, Squares of fitted values

\begin{tabular}{llll}
\hline \hline & Value & DF & Probability \\
\cline { 2 - 4 } t-statistic & 0.998145 & 89 & 0.3209 \\
F-statistic & 0.996293 & $(1,89)$ & 0.3209 \\
\hline \hline
\end{tabular}

Breusch-Godfrey-Serial-Correlation LM Test

\begin{tabular}{lcll}
\hline \hline F-statistic & 0.211900 & Prob-F(2,88) & 0.8095 \\
Obs, ${ }^{*}$ R-squared & 0.450525 & Prob-Chi-Square(2) & 0.7983 \\
\hline \hline Heteroskedasticity Test; Breusch-Pagan-Godfrey & & \\
\hline \hline F-statistic & 0.124651 & Prob-F(4,89) & 0.9732 \\
Obs, ${ }^{*}$ R-squared & 0.523680 & Prob-Chi-Square(4) & 0.9712 \\
Scaled-explained SS & 0.950968 & Prob-Chi-Square(4) & 0.9171 \\
\hline \hline
\end{tabular}

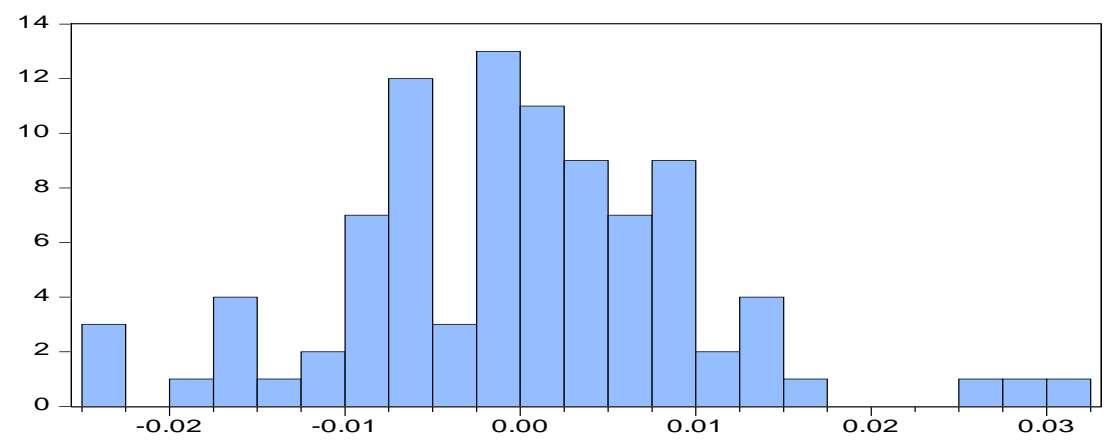

$\begin{array}{lc}\text { Series: Residuals } \\ \text { Sample 1995Q12017Q4 } \\ \text { Observations } 92 \\ \text { Mean: } & 7.73 e-19 \\ \text { Median: } & -0.000261 \\ \text { Maximum } & 0.030817 \\ \text { Minimum } & -0.024593 \\ \text { Std. Dev. } & 0.010279 \\ \text { Skewness } & 0.236654 \\ \text { Kurtosis } & 3.973181 \\ & \\ \text { Jarque-Bera } & 4.489230 \\ \text { Probability } & 0.105968\end{array}$


Schwarz Criteria (top 20 models)
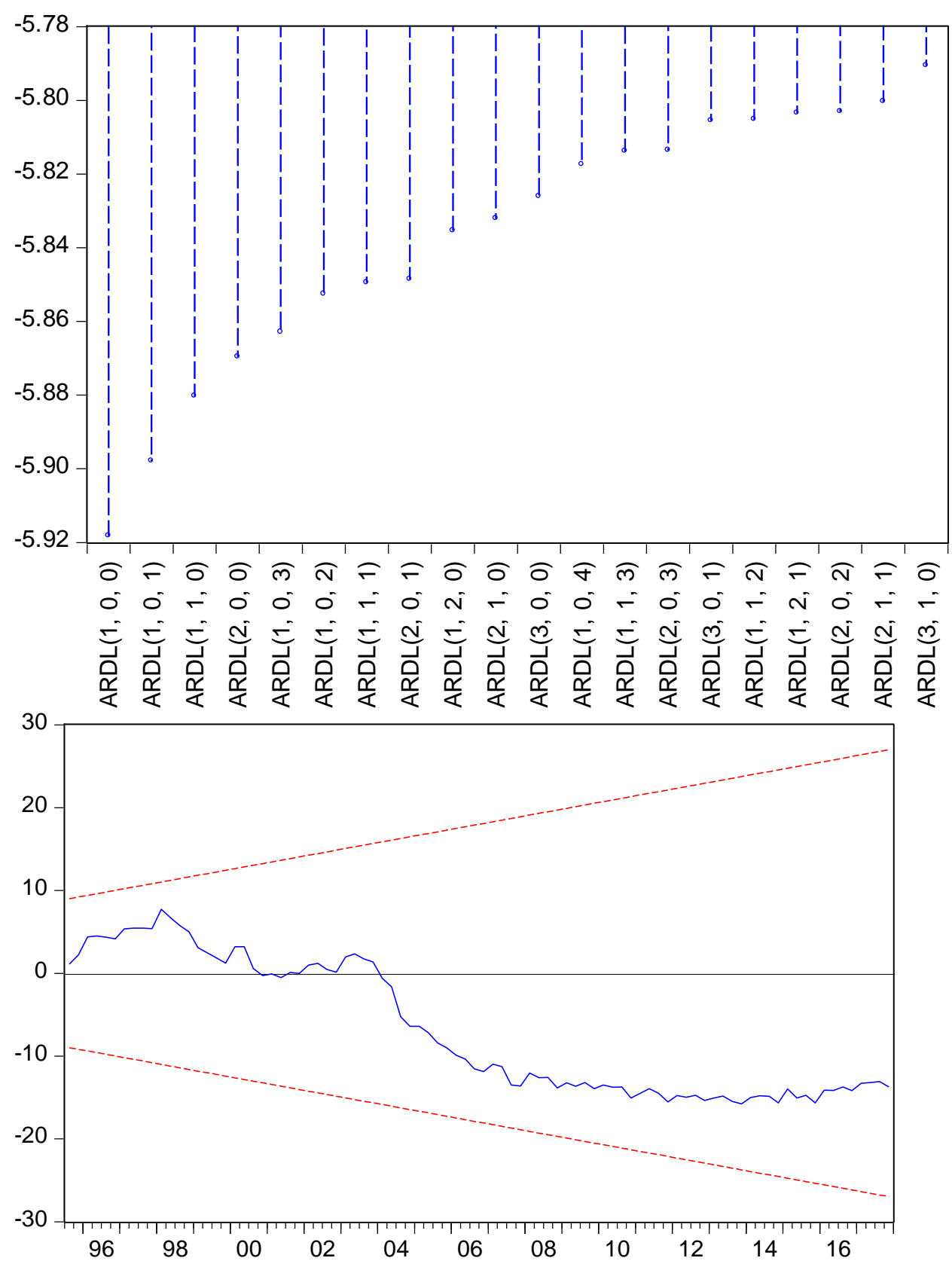

_ CUSUM --- 5\% Significance 